\title{
Impaired In-vitro Platelet Aggregation and Secretion Tests in Children with Henoch-schöenlein Purpura
}

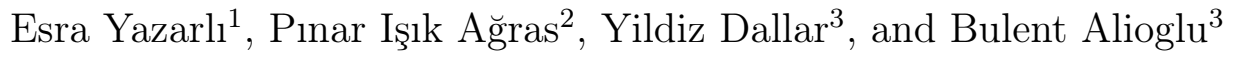 \\ ${ }^{1}$ Mustafa Kemal Universitesi Tayfur Ata Sokmen Tip Fakultesi \\ ${ }^{2}$ Ankara Güven Hospital \\ ${ }^{3}$ Ankara Training and Research Hospital
}

March 27, 2021

\begin{abstract}
Abstract Aim: This study aimed to investigate the in-vitro platelet aggregation and secretion tests in children patients with Henoch-schöenlein Purpura that recently referred to as Ig A vasculitis Methods: This is a cross-section study that included 55 patients with Henoch-schöenlein Purpura and 31 healthy children as a control group. Children who have a history of drug use, chronic diseases, and bleeding diseases were excluded from the study. Complete blood count, thrombocyte aggregation, and secretion tests were studied in both groups. These tests were re-evaluated in remission of the disease. Results: It was found that epinephrine-stimulated platelet aggregation and collagen, epinephrine, ristocetin, arachidonic acid, standard dose thrombin, and high dose thrombin-stimulated platelet secretion results were lower in the patients with Henoch-schöenlein Purpura compared to the healthy control group in the acute period (respectively $\mathrm{P}=0.014,0,003 ; 0,003 ; 0,027 ; 0,034 ; 0,010 ; 0,049$ ). When the values of patients with Henoch-schöenlein Purpura in the acute period and the remission of the disease were compared, collagenstimulated platelet aggregation and epinephrine-stimulated platelet secretion values were found to be lower in patients with patients in the acute period $(\mathrm{P}=0.016 ; 0.039)$ Conclusion: Impairment in vitro platelet aggregation and secretion tests in the patients with Henoch-schöenlein Purpura suggest that the tendency to bleeding in these patients may be due to platelet impairment function. Key Words: Henoch-schöenlein Purpura, platelet aggregation tests, platelet secretion tests, children, Ig A vasculitis. What's already known about this topic? There is a tendency to bleeding in Henoch Shcöenlein Purpura patients, such as gastrointestinal bleeding, nonthrombocytopenic system purpura. What does this article add? It was found that impairment in-vitro platelet aggregation and secretion tests in Henoch Shcöenlein Purpura patients.
\end{abstract}

\section{Introduction}

Henoch-schöenlein Purpura (HSP), recently more commonly referred to as Ig A vasculitis, is the most common leukocytoclastic vasculitis of small vessels in childhood ([1]. It affects the especially skin and gastrointestinal system, joints, kidneys, rarely other organs. Nonthrombocytopenic purpura, gastrointestinal system bleeding, abdominal pain, arthritis, nephritis, and testicular involvement may occur during the disease [2]. Most cases occur after upper respiratory tract infection. Drugs and vaccines also have been reported to be triggered $[3-5]$.

Although Ig A accumulation has been demonstrated in the affected organs' small vessels, the etiopathogenesis is still elucidated $[6,7]$. It is thought that triggering factors cause endothelial dysfunction by stimulating the vascular endothelium. This situation plays an important role in pathogenesis [8,9]. Platelets have multiple functions, including hemostasis, inflammation, host defenses, vascular tone. The endothelium has an important role in the regulation of hemostasis. When vascular endothelium is damaged, vasocontraction occurs in vascular smooth muscle, and platelets come together to form the platelets plug [10]. Purpuric rashes, hematuria, hematemesis, and melena in patients with HSP suggest that coagulation disorders may 
occur [11]. The fact that platelet count, bleeding time, clotting time, prothrombin time, and activated partial thromboplastin time were normal in patients suggest that it is due to vascular cause rather than coagulation disorders [12]. However, in some studies, it has been reported that platelet functions are impaired in patients with HSP $[13,14]$. This study aimed to evaluate in vitro platelet aggregation and secretion tests in patients with HSP, an essential vasculitis of childhood.

\section{Methods}

The study included 55 patients with HSP and 31 healthy children as a control group. EULAR/PRES classification criteria were used for the diagnosis of HSP [15]. The control group with no health problems that were admitted for routine check-ups enrolled at pediatric outpatient clinics. Children with known chronic diseases and bleeding diseases were excluded from the study. Patients with a history of drug use were not included in the study.

The study was approved by the local ethics committee. Informed parental consent was obtained for all children.

Complete blood count, thrombocyte aggregation, and thrombocyte secretion tests were studied in the acute phase of the disease. 24 patients with HSP did not continue the study for various reasons. Thrombocyte function tests of 21 continuing to study patients with HSP were re-evaluated in remission of the disease.

For complete blood count tests, two cc of blood was taken from the antecubital vein for each patient and healthy control groups into one standard tube containing 7.5\% K3- ethylenediaminetetraacetic acid solution was used. White blood cell, absolute neutrophil count, absolute lymphocyte counts, absolute monocyte count, platelet count, mean platelet volüme, absolute neutrophil count, absolute lymphocyte, and absolute monocyte counts hemoglobin were measured. For platelet aggregation and secretion tests, four cc of blood was taken from the antecubital vein for each patient and healthy control groups into two standard tubes containing $0.5 \mathrm{ml}$ (1 volume) of $0.109 \mathrm{M}$ trisodium citrate solution. Platelet aggregation tests were carried out with the American origin Chronolog Corporation (model 700) brand device using the optical aggregometer method. Platelet secretion tests were also studied with the American Chronolog Corporation (model 700) device using the lumiaggregometry method. Collagen $(2 \mu \mathrm{g} / \mathrm{mL})$, epinephrine $(5 \mu \mathrm{M})$, standard dose of ADP $(5 \mu \mathrm{M})$, high dose of ADP $(10 \mu \mathrm{M})$, standard dose of thrombin [1 unit $(30 \mu \mathrm{L})]$, high dose of thrombin [4 units $(30 \mu \mathrm{L})]$, ristocetin $(1.25 \mathrm{mg} / \mathrm{mL})$, and arachidonic acid $(0.5 \mathrm{mM})$ were used as agonists to test for platelet aggregation and secretion

Data analysis was performed using SPSS for Windows 11.5 package program. Shapiro Wilk test was used to determine whether the distribution of continuous variables was normal. Descriptive statistics were shown as mean \pm standard deviation for continuous variables and nominal variables as the number of cases (percentages \%). Continuous variables with normal distribution between the groups were investigated by the student's t-test, and continuous variables were not normally distributed with the Mann-Whitney U test. Wilcoxon test was used to determine a statistically significant change between the values measured in the acute period and the remission of the disease.

Results

Mean age of the patient and healthy control group (patient group $8.3 \pm 3.2$ years and healthy control group $7.7 \pm 3.7$ years; $\mathrm{p}=0.265$ ) and gender distribution (patient group 31 girls $(56.4 \%)$ and 25 boys (43.6\%); healthy control group 15 girls $(48.4 \%)$ and 16 boys $(51.6 \%) ; \mathrm{p}=0.476)$ were statistically similar.

When the clinical features of the patient group were evaluated; in $55(100 \%)$ patients skin involvement, in $13(25 \%)$ patients arthritis, in $10(19.2 \%)$ patients gastrointestinal involvement, in $2(3.8 \%)$ patients renal involvement and in $2(3.8 \%)$ patients genitourinary system involvement were detected. Steroid treatment was administered to $14(25.4 \%)$ patients, including gastrointestinal involvement 10, severe skin involvement 2 , renal involvement 2 .

In the acute period, the white blood cell count, absolute neutrophil count, absolute lymphocyte, and absolute 
monocyte counts were found to be higher in patients with HSP compared to the control group ( respectively $P$ $<0,001 ; 0,001 ; P=0,010$ ve 0,044$)$ (Table 1 ). When the platelet aggregation tests were examined, epinephrinestimulated platelet aggregation test results were lower in patients with HSP $(\mathrm{P}=0.014)$ (table 2). However, there were no differences between the two groups in terms of collagen, standard dose ADP, arachidonic acid, standard dose thrombin, high dose thrombin, ristocetin cofactor, high dose ADP, and ristocetin-stimulated platelet aggregation results (table2). When compared in term of platelet secretion tests, collagen, epinephrine, ristocetin, arachidonic acid, standard dose thrombin and high dose thrombin-stimulated platelet secretion results were found to be lower in patients with HSP ( respectively $P=0,003 ; 0,003 ; 0,027 ; 0,034 ; 0,010$; 0,049) (Table 2). However, there was no difference between the two groups in terms of standard-dose ADP and high dose ADP-stimulated platelet secretion results (table2).

When the values of 21 patients with HSP in the acute period and the remission of the disease were compared, it was found that the white blood cell count, platelet count, absolute neutrophil count, and absolute monocyte count were higher in the acute period (respectively $P=0,011 ; 0,001 ; 0,011 ; 0,044$ ) (Tablo3). When platelet aggregation tests were examined, collagen-stimulated platelet aggregation values were found to be lower in patients with HSP in the acute period $(P=0.016)$ (Tablo 4). However, no difference was found in epinephrine, standard dose ADP, high dose ADP, standard dose thrombin, high dose thrombin, ristocetin cofactor, and arachidonic acid- stimulated platelet aggregation results between the values measured in the acute period and the remission of the disease. When platelet secretion tests were examined, epinephrine-stimulated platelet secretion value was lower in patients with HSP in the acute period $(P=0.039)$ (Tablo 4$)$. There was no difference between the values of arachidonic acid, standard dose thrombin, high dose thrombin, standard dose ADP, high dose ADP, collagen, and ristocetin-stimulated platelet secretion results in the acute period and the remission of the disease.

\section{DISCUSSION}

Although the presence of clinical conditions such as purpuric rash, hematuria, hematemesis, and melena without thrombocytopenia in patients with HSP has been attributed to the vasculitis state, there are also various publications suggesting that coagulation disorders may be present [13, 14].

Studies on mean platelet volüme showing platelet function and activation have also increased in HSP patients in recent years. Xiang Shi et al.[16] conducted a study with 97 patients with HSP and 120 healthy children as a control group. The mean platelet volüme was significantly lower in patients with HSP than in the control group. It was found that the mean platelet volüme of the patients in the acute phase was also lower than the recovery period.

In some past publications, impaired coagulation system has also been reported patients with HSP. A study of 54 patients with HSP, prolonged platelet aggregation, decreased plasminogen, decreased antithrombin III, and increased fibrin monomers [14]. In another study conducted with 23 adult patients with HSP, impairment platelet aggregation with ADP was shown in patients with HSP [17].

ADP and epinephrine stimulated platelet aggregation tests were evaluated in another study conducted with 11 male and 13 female patients aged 4-12 years with HSP. It was found that block in ADP release in 58.3\% of patients, severe deterioration in aggregation in $29.2 \%$, whereas ADP -stimulated aggregation tests were reported as normal in $8.3 \%$ of patients [13].

In our study, when platelet aggregation and platelet secretion tests were examined in patients with HSP, the results of epinephrine-stimulated platelet aggregation and collagen, epinephrine, ristocetin, arachidonic acid, standard dose thrombin, and high dose thrombin-stimulated platelet secretion results in children with HSP, we found that lower than the control group. 24 of 55 patients were excluded from to study for various reasons. Thrombocyte function tests of 21 patients with HSP who were continuing to study were rechecked to remission of the disease. In 21 patients with HSP, platelet aggregation results stimulated with collagen and ristocetin were found to be lower in the acute period than the value measured in the remission of the disease. When platelet secretion tests were examined, epinephrine-stimulated platelet secretion results were found to 
be lower than the value measured in the acute period compared to the value measured in the remission of the disease. These results show that HSP children have impaired in-vitro platelet aggregation and secretion in the acute phase.

As a result of our study, impairment in-vitro platelet aggregation and secretion tests in the patients with HSP suggest that the tendency to bleeding in these patients may be due to the impairment of platelet function. There are a few studies in the literatüre on platelet function tests in patients with HSP. We believe that to elucidate better the pathogenesis of bleeding tendency in patients with HSP, more extensive and further studies are needed on this subject.

Limitations: 24 of the 55 patients participating were excluded from our study. The number of cases examined in vitro platelet aggregation and secretion tests during the remission period decreased.

\section{References}

1. Jennette JC FR, Bacon PA, Basu N, Cid MC, Ferrario F, Flores-Suarez LF, et al. 2012 revised international Chapel Hill consensus conference nomenclature of vasculitides. Arthritis Rheum 2013; 65 : 1-11.

2. McCarthy HJ, Tizard EJ. Clinical practice: Diagnosis and management of Henoch-Schonlein purpura. European journal of pediatrics 2010; $169: 643-50$.

3. Aktas B TP, Kurt OK, Ensari A, Demirer T. Severe Henoch-Schönlein Purpura Induced by Cytarabine. Ann Pharmacother 200943 : 792-3.

4. Watanabe T. Henoch-Schonlein purpura following influenza vaccinations during the pandemic of influenza A (H1N1). Pediatric nephrology 2011; $26: 795-8$.

5. Jariwala S VN, Shliozberg J. Henoch-Schonlein purpura after hepatitis A vaccination. Ann Allergy Asthma Immunol 2011; $107: 180-1$.

6. Hetland LE, Susrud KS, Lindahl KH, Bygum A. Henoch-Schonlein Purpura: A Literature Review. Acta dermato-venereologica 2017; $97: 1160-6$.

7. Heineke M. H, Ballering, A.V, Jamin A, Ben Mkaddem, S, Monteiro, R. C, Van Egmond M. New insights in the pathogenesis of immunoglobulin A vasculitis (Henoch-Schonlein purpura). Autoimmunity reviews 2017; 16 : $1246-53$.

8. Kurotobi S, Kawakami N, Honda A, Matsuoka T, Hara T, Nagai T, et al. Impaired vascular endotheliumdependent relaxation in Henoch-Schonlein purpura. Pediatric nephrology 2004; 19 : 138-43.

9. Dursun I, Dusunsel R, Poyrazoglu HM, Gunduz Z, Patiroglu T, Ulger H, et al. Circulating endothelial microparticles in children with Henoch-Schonlein purpura; preliminary results. Rheumatology international 2011; 31 : 1595-600.

10. Van der Poll T, Parker RI. Platelet Activation and Endothelial Cell Dysfunction. Critical care clinics 2020; 36 : 233-53.

11. Culic S JR. Purpura anaphylactoides (Schöenlein-Henoch) in childhood as the consequence of immune vasculitis and immune thrombocytopathia. Thromb Haemost Abstracts XVI Congress of the International Society on Thrombosis and Haemostasis Florence, Italy (Suppl)June 1997: p. 272.

12. Edekmann CM Jr BJ, Meadow SR, Spitter A, Travis LB. Schonlein-Henoch Syndrome. In: Pediatric Kidney Disease, (2nd edition), Little, Brown and Company 1992: 1525-33.

13. Culic S JR, Metlicic V, Paukovic-Sekulic B, Resic B, Culic V, Kuljis D, Primorac D. Platelet function analysis in children with Schonlein-Henoch syndrome. Arch Med Res 2001; 32 : 268-72.

14. Mishkova R. KK, Petrova E. Hemostatic disorders in patients with Schoenlein-Henoch syndrome, in Russian. Klin Med (Mosk) 1990; $68:$ 47-9. 
15. Ozen S, Ruperto N, Dillon MJ, Bagga A, Barron K, Davin JC, et al. EULAR/PRES endorsed consensus criteria for the classification of childhood vasculitides. . Ann Rheum Dis 2006; 65 : 936-41.

16. Shi X, Li WC, Mo LJ, Li XH, Luo YZ, Qin LQ, et al. Altered mean platelet volume in children with Henoch-Schonlein purpura and its association with disease activity. Annals of clinical biochemistry 2018; 55 : 368-72.

17. Boros G GL, Sámsik J, Nagy J, Hámori A, Deák G . Blood coagulation abnormalities in the SchönleinHenoch syndrome in adults. Acta Med Acad Sci Hung 1979;36 : 151-66.

\section{Hosted file}

Tables.pdf available at https://authorea.com/users/391087/articles/515544-impaired-in-vitroplatelet-aggregation-and-secretion-tests-in-children-with-henoch-sch\%C3\%B6enlein-purpura 